\title{
Association of COL1A1, COL5A1, MMP1 gene polymorphisms with skin metabolism in a Caucasian Greek population
}

\author{
Olympia Bimi, Eleni Vounta, Martha - Spyridoula Katsarou, Vasilios Desiniotis, \\ Theodoros Kalogridis, Maria Lagiou, Nikolaos Drakoulis
}

Research Group of Clinical Pharmacology and Pharmacogenomics, Faculty of Pharmacy, School of Health Sciences, National and Kapodistrian University of Athens, Greece

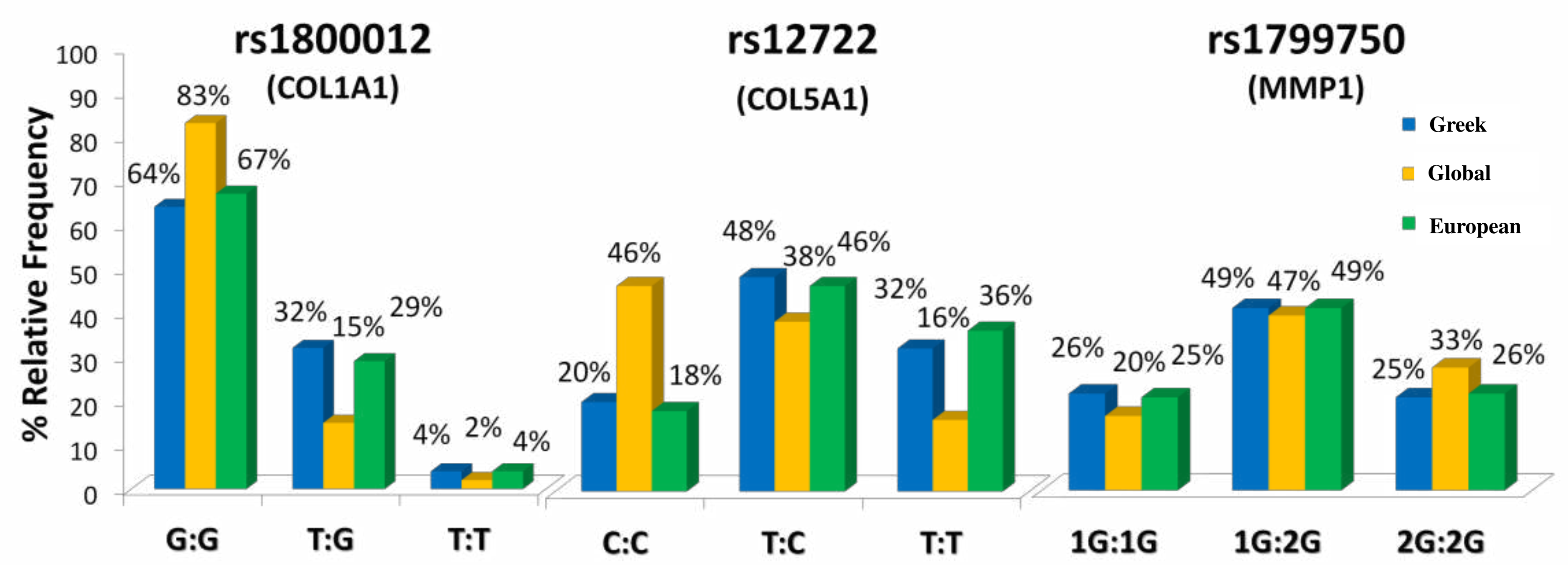

Chart 1. Comparative chart with genotypes incidence rates of polymorphisms rs1800012, rs12722 and rs1799750 in Greek, Global and European population.

\section{Background}

Collagens are the most abundant proteins in the human body. Collagen molecules are constituted of three alpha (a) polypeptidic chains. COL1A1 and COL5A1 genes encode a1 chains of collagen type I and type $V$, respectively. In this study, we will focus on the variants rs 1800012 of COL1A1 gene and rs12722 of COL5A1 gene, which interfere in the collagen structure and the rs1799750, a variant of the MMP1 gene which induces the collagen metabolism.

The rs1800012 (G/T) showed association with skin thickness and keloid scars. The rs12722 (C/T) was associated with a connective tissue disorder, the Ehlers-Danlos classic type Syndrome. The rs1799750, an insertion polymorphism in the MMP1 gene $(-/ G)$ was associated with dystrophic epidermolysis bullosa, a skin fragility disorder.

\section{Purpose}

Through this study we aim to reveal the genetic penetrance of the variants as well as to estimate the susceptibility of developing dermopathies in a sample of 1402 Caucasian volunteers. Finally we hope that our findings can contribute to the utilization of personlized therapy for a more efficient treatment of the aforementioned pathological condition.

\section{Materials and Methods}

DNA extraction from oral epithelial cells, followed by real time PCR assays led to the determination of the individuals" genotype, which were processed thus enabling the calculation of the variants frequencies.

\begin{tabular}{ccccccc}
\hline $\begin{array}{c}\text { Poly- } \\
\text { morphism }\end{array}$ & Alleles & Frequency & $\%$ & $\begin{array}{c}\text { Geno- } \\
\text { types }\end{array}$ & Frequency & $\%$ \\
\hline rs1800012 & $\mathrm{G}$ & 2236 & 79,74 & $\mathrm{GG}$ & 896 & 63.91 \\
(COL1A1) & $\mathrm{T}$ & 568 & 20,26 & $\mathrm{TG}$ & 444 & 31,67 \\
& & & & $\mathrm{TT}$ & 62 & 4,42 \\
rs12722 & $\mathrm{C}$ & 1227 & 43,45 & $\mathrm{CC}$ & 275 & 19,61 \\
(COL5A1) & $\mathrm{T}$ & 1597 & 56,55 & $\mathrm{CT}$ & 677 & 48,29 \\
& & & & TT & 450 & 32,10 \\
rs1799750 & 1G & 1416 & 50,50 & $1 \mathrm{G} 1 \mathrm{G}$ & 365 & 26,03 \\
(MMP1) & 2G & 1388 & 49,50 & 2G2G & 686 & 48,93 \\
& & & & 2G2G & 351 & 25,04 \\
\hline
\end{tabular}

Table 1. Frequency distribution of alleles and genotypes of polymorphisms rs1800012, rs12722 and rs1799750 .

\section{Results}

For $r 51800012$ the frequency of the $\mathrm{G}$ allele in our study group was $79,74 \%$ and of the mutated T, 20,26\%. For rs 12722 the $43,45 \%$ of population carried the $C$ allele and the $56,55 \%$ the mutated T. For rs 1799750 the $49,50 \%$ of the volunteers presented a G insertion in the MMP1 gene.

\section{Conclusions}

The comparison of our results with the frequency distribution of studied genetic variants in the European population, presented no significant differences between the two populations. These findings coincide with our expectations due to the fact that our volunteers are characterized as South-Eastern Europeans, despite the influence of populations with different origins. 